\title{
Redes sociales y plataformas de fact-checking contra la desinformación sobre la COVID-19
}

\author{
Xavier Ramon-Vegas \\ Universitat Pompeu Fabra \\ xavier.ramon@upf.edu \\ https://orcid.org/0000-0002-4478-5626
}

\author{
Marcel Mauri-Ríos \\ Universitat Pompeu Fabra \\ marcel.mauri@upf.edu \\ https://orcid.org/0000-0003-2615-8343
}

\author{
Ruth Rodríguez-Martínez \\ Universitat Pompeu Fabra \\ ruth.rodriguez@upf.edu \\ https://orcid.org/0000-0001-5633-6126
}

\section{Social media and fact-checking platforms against disinformation about COVID-19}

\section{RESUMEN ABSTRACT}

La pandemia de la COVID-19 ha generado una crisis sanitaria y comunicativa sin precedentes. A través de las plataformas digitales, se ha producido una ingente circulación de información falsa, inexacta o descontextualizada sobre el coronavirus. Entre ella, cabe destacar los rumores, bulos y teorías conspirativas sobre (1) el origen, expansión y letalidad del virus; (2) las recomendaciones y prácticas curativas; y (3) la gestión de la pandemia por parte de las administraciones públicas y organismos internacionales.

En el actual escenario de infodemia, esta investigación aborda de qué forma 8 organizaciones de fact-checking han empleado Twitter como herramienta para combatir la desinformación en tiempos de la COVID-19: Agência Lupa

(Brasil), Chequeado (Argentina), Maldita.es y Newtral (España), Colombia-Check (Colombia), Ecuador Chequea (Ecuador), El Sabueso - Animal Político (México) y Cotejo (Venezuela). Entre los meses de marzo y junio de 2020 estas organizaciones han publicado de forma sostenida en Twitter, obteniendo elevadas cifras de engagement en forma de retuits y favoritos. Se han incluido múltiples hashtags sobre

la COVID-19, incluyendo aquellas eti-quetas promovidas

por LATAM Chequea y la IFCN (\#CoronaVirusFacts y \#Datos(oronaVirus) y otros hashtags genéricos dirigidos al gran público. Los contenidos relacionados con la COVID-19 han sido los más viralizados por los usuarios.

PALABRAS CLAVE

Fact-checking; Verificación; Desinformación; COVID-19; Redes sociales; Twitter.
The COVID-19 pandemic has generated an unprecedented health and communication crisis. Through digital platforms, there has been a huge circulation of false, inaccurate or decontextualized information about the coronavirus. Among them, it is worth mentioning the rumors, hoaxes and conspiracy theories about (1) the origin, spread and lethality of the virus; (2) recommendations and curative practices; and (3) management of the pandemic by public administrations and international organizations. In the current infodemic scenario, this research addresses how 8 fact-checking organizations have used Twitter as a tool to combat disinformation in the times of COVID-19: Agência Lupa (Brazil), Chequeado (Argentina), Maldita.es and Newtral (Spain), ColombiaCheck (Colombia), Ecuador Check (Ecuador), El Sabueso - Animal Político (Mexico) and Cotejo (Venezuela). Between March and June 2020, these organizations have published on Twitter on a sustained basis, obtaining high engagement figures in the form of retweets and favorites. Multiple hashtags on COVID-19 have been included, including those tags promoted by LATAM Chequea and IFCN (\#CoronaVirusFacts and \#DatosCoronaVirus) and other generic hashtags aimed at the general public. The contents related to COVID-19 have been the most viralized by users.

\section{KEYWORDS}

Fact-checking; Verification; Disinformation; COVID-19; Social media; Twitter. sobre la COVID-19. Hipertext.net, (21), 79-92. https://doi.org/10.31009/hipertext.net.2020.i21.07 


\section{Introducción}

La pandemia derivada de la expansión de la COVID-19 ha generado una crisis sanitaria sin precedentes y con fuertes implicaciones en todos los ámbitos de la sociedad. Esta situación también ha supuesto una crisis de primer orden en el ámbito comunicativo. En febrero de 2020, la Organización Mundial de la Salud acuñó el término infodemia (OMS, 2020) para referirse a la sobreabundancia de información sobre la COVID-19 que circula a través de múltiples plataformas. Al gran volumen de datos verdaderos e información contrastada, se le suma la ingente circulación de información falsa, inexacta o descontextualizada sobre el coronavirus. Entre ella, cabe destacar los rumores, bulos y teorías conspirativas sobre el origen, expansión y letalidad del SARS-CoV-2, así como sobre las recomendaciones y prácticas curativas (Pérez-Da Silva et al., 2020; Pulido et al., 2020; Sánchez-Duarte y Magallón-Rosa, 2020). A la desinformación sobre ciencia y salud se le suma aquella referente a los aspectos políticos y gubernamentales de la gestión de la pandemia por parte de las administraciones públicas y organismos internacionales (Salaverría et al., 2020). La gran mayoría de desinformación sobre la COVID-19 no se fundamenta en la invención, sino en la reconfiguración, recontextualización o distorsión de materiales preexistentes (Brennen et al., 2020).

La desinformación representa un reto de primera magnitud en el escenario actual, puesto que su difusión "eventualmente puede conducir a falsas creencias o percepciones erróneas, hecho que plantea grandes problemas en la toma de decisiones democráticas" (Hameleers y van der Meer, 2020, p. 230). La expansión de la desinformación no puede comprenderse sin tener en cuenta las transformaciones tecnológicas que han alterado el ecosistema comunicativo en los últimos años. La expansión de las plataformas digitales ha facilitado la multiplicación de oportunidades para la producción, difusión y consumo de información. Los medios de comunicación han encontrado en las redes sociales nuevos espacios para entrar en contacto con las fuentes y maximizar la distribución de sus contenidos (Houston et al., 2020). Nuevos actores individuales y colectivos - también han emergido y han aprovechado estas plataformas para difundir información y participar activamente en la esfera pública digital.

Sin embargo, la democratización derivada de la revolución digital ha añadido complejidad al ecosistema comunicativo. Como señalan Ruiz et al. (2010, p. 10), los nuevos espacios propiciados por la tecnología se han convertido en avenidas por donde transitan inmensos caudales de opinión que posibilitan la impunidad desde la participación muchas veces anónima". Desde la óptica de la desinformación, redes sociales como Twitter, Facebook y WhatsApp han propiciado la difusión de "información fabricada que imita astutamente las noticias y aprovecha las creencias públicas existentes para influir y desestabilizar a la sociedad y las instituciones" (Casero-Ripollés, 2020, p. 3). Como señalan Masip et al. (2020, p. 11), las redes sociales se configuran "como el entorno principal de difusión de bulos, muy por delante de los medios periodísticos y de otros canales de comunicación interpersonal como, por ejemplo, los SMS o el correo electrónico".

Durante la pandemia de la COVID-19, el consumo de noticias por parte de la ciudadanía se ha incrementado de forma notoria (Casero-Ripollés, 2020; Lázaro-Rodríguez y Herrera-Viedma, 2020). En particular, el consumo de información a través de las plataformas digitales y las redes sociales ha crecido de forma significativa debido a su capacidad de actualización permanente (Masip et al., 2020). Sin embargo, la aceleración de los flujos informativos en el entorno digital, combinada con la incertidumbre de la situación presente, ha propiciado "las condiciones perfectas para la creación y difusión de desinformaciones" (Sánchez-Duarte y Magallón-Rosa, 2020, p. 36). Como componente esencial de su función de servicio público, las empresas periodísticas han intensificado su cobertura sobre el coronavirus, tratando a su vez de desmentir aquellas informaciones que pudiesen representar un riesgo sobre la salud y bienestar de las personas. Sin embargo, debido a la escasez de recursos en el momento actual, las organizaciones periodísticas por si solas "no disponen de las capacidades para limpiar un ecosistema digital contaminado" (López-Pan y Rodríguez-Rodríguez, 2020, p. 1046). En este contexto, la tarea de otros agentes independientes, como las plataformas de fact-checking, adquiere un valor fundamental.

Las organizaciones de fact-checking son conceptualizadas como intervenciones que aparecen "cuando se percibe una amenaza" (Amazeen, 2020, p. 98). Ante la situación excepcional que nos ocupa, las plataformas independientes de fact-checking han jugado un papel clave para contrarrestar la circulación de informaciones falsas durante la pandemia de la COVID-19 (Brennen et al., 2020). Además de proporcionar información fiable a través de fuentes oficiales, estas plataformas han habilitado secciones o especiales en sus sitios web y han intensificado su actividad en redes sociales para luchar 
contra la desinformación en línea.

\section{Plataformas de fact-checking: agentes clave en la lucha contra la desinformación}

Pese a que el fact-checking interno a los medios de comunicación apareció en Estados Unidos durante las primeras décadas del siglo XX, las plataformas de fact-checking modernas son mucho más recientes (Amazeen, 2020). En el seno del Annenberg Public Policy Center de la University of Pennsylvania (EE.UU.) se creó en 2003 la plataforma FactCheck.org. Esta fue seguida por las experiencias de Channel 4 (2005), The Washington Post's Fact Checker y PolitiFact.com (2007), Libération (2008) y Le Monde (2009). El crecimiento de desinformación vinculada a procesos electorales ha facilitado la expansión de las plataformas de fact-checking a nivel global.

En la actualidad, según el censo elaborado por el Reporters' Lab de la Sanford School of Public Policy de la Duke University, hay 290 plataformas de fact-checking activas en 83 países (Stencel y Luther, 2020). Según Graves y Cherubini (2016) existen dos modelos de organizaciones de fact-checking: aquellas unidades impulsadas por medios de comunicación (newsroom model) y aquellos proyectos creados de forma independiente (NGO model). Pese a estas diferencias, de acuerdo con el código de principios de la International Fact-Checking Network (IFCN), creada en 2015 por el Poynter Institute for Media Studies, todas las organizaciones de fact-checking deben caracterizarse por su imparcialidad, transparencia (fuentes empleadas, financiación, organización y metodología) y por ofrecer una política de correcciones abierta y honesta.

De forma esencial, las metodologías de trabajo de estas organizaciones pivotan sobre la siguiente secuencia de trabajo: (1) Seleccionar una frase del ámbito público y ponderar su relevancia; (2) Contactar a la fuente original; (3) Consultar fuentes oficiales y alternativas; (4) Puesta en contexto de la afirmación; y (5) Calificar la afirmación según las categorías establecidas (Moreno-Gil, Ramon-Vegas y Rodríguez-Martínez, 2021). Este marco general se adapta para abordar la desinformación en Internet y las redes sociales. Como en muchos casos no es posible contactar con la fuente original, se emplean herramientas online y otras metodologías como las entrevistas para verificar los datos. En el complejo escenario actual, también es frecuente que determinadas verificaciones no se realicen mediante la consulta de fuentes, sino que requieran en primera instancia el uso de herramientas tecnológicas como la búsqueda invertida de Google, TinEye o FotoForensics (Brandtzaeg, Følstad y Chaparro-Domínguez, 2018).
Como se indicará posteriormente, en muchas ocasiones los materiales a verificar son propuestos por ciudadanos anónimos a través de servicios habilitados por las propias plataformas, como canales de WhatsApp (Molina-Cabañate y Magallón-Rosa, 2020; Ufarte-Ruiz, Anzera y Murcia-Verdú, 2020).

Pese a operar con escasez de recursos y equipos limitados (Humprecht, 2020; Lowrey, 2017), las plataformas de fact-checking se caracterizan por hacer un uso intensivo de las herramientas digitales y las redes sociales para desarrollar las verificaciones, difundir su trabajo y establecer un contacto directo con los lectores (Brandtzaeg, Følstad y Chaparro-Domínguez, 2018; Graves, 2018; Singer, 2018). Como es sabido, las redes sociales son "un espacio muy útil por su enorme repercusión y visibilidad entre los consumidores de medios" (Ramon-Vegas y Mauri-Ríos, 2020, p. 70). En la era de la deliberación digital (Masip, Ruiz y Suau, 2019), gracias a estos canales las audiencias pueden mandar comentarios, materiales y sugerir la realización de verificaciones. De este modo, "el ciudadano se erige en una figura de gatekeeper al identificar, seleccionar y enviar a los periodistas esas informaciones virales que circulan en el entorno digital sobre temas de actualidad o controvertidos que requieren ser verificados" (Rodríguez-Pérez, 2020, p. 247). Para las organizaciones de fact-checking, las redes sociales como Twitter también son un espacio clave para generar tráfico y maximizar el engagement de sus contenidos a través de retuits y favoritos. Mediante estas acciones de participación, los usuarios se convierten en corresponsables de viralizar la verdad.

En los últimos años, los análisis académicos de las plataformas en el contexto estadounidense han dado paso a un espectro más amplio contribuciones, que han ahondado en las características, el funcionamiento y el contenido elaborado por plataformas de fact-checking en Europa y África (Cheruiyot y Ferrer-Conill, 2018; Haigh, Haigh y Kozak, 2018; Humprecht, 2019; Singer, 2020). Investigaciones recientes han ahondado específicamente en los métodos, estructuras y temas tratados por las plataformas de fact-checking en España y América Latina (Bernal-Triviño y Clares-Gavilán, 2019; López-Pan y Rodríguez-Rodríguez, 2020; Molina-Cañabate y Magallón-Rosa, 2020; Palau-Sampio, 2018; Rodríguez-Pérez, 2020; Ufarte-Ruiz, Anzera y Murcia-Verdú, 2020; Ufarte-Ruiz, Peralta-García y Murcia-Verdú, 2018; Vizoso y Vázquez-Herrero, 2019).

La colaboración estratégica entre organizaciones de Iberoamérica ha cristalizado en iniciativas como la red LATAM Chequea, impulsada por Chequeado en 2014 con el objetivo de compartir aprendizajes, experiencias 
y herramientas para la verificación de información. Los 35 miembros de esta alianza participan en la plataforma "Información chequeada sobre el Coronavirus" (https:// chequeado.com/latamcoronavirus/), desarrollada para combatir la desinformación sobre la COVID-19. Además de la participación en este proyecto, las organizaciones de fact-checking han desarrollado una intensa tarea de publicación de verificaciones en sus sitios web y cuentas en redes sociales, donde han empleado hashtags como \#CoronaVirusFacts y \#DatosCoronaVirus. En el marco de la crisis de la COVID-19, resulta especialmente relevante examinar la tarea realizada por las plataformas de fact-checking para combatir la desinformación a través de la publicación de verificaciones a través de las redes sociales, y en particular, a través de Twitter.

\section{Objetivos y metodología}

El objetivo principal de esta investigación es abordar de qué forma las siguientes plataformas de fact-checking de 7 países en América Latina y España emplean la red social Twitter como herramienta para combatir la desinformación en tiempos de la COVID-19: Agência Lupa (Brasil), Chequeado (Argentina), Maldita.es y Newtral (España), ColombiaCheck (Colombia), Ecuador Chequea (Ecuador), El Sabueso - Animal Político (México) y Cotejo (Venezuela). Este objetivo principal se concreta en los siguientes objetivos específicos (OE):

- OE1. Conocer el volumen y frecuencia de publicación de contenidos de las plataformas de fact-checking en Twitter.

- OE2. Examinar las cifras de engagement -retuits y favoritos- obtenidas por las plataformas de fact-checking en Twitter.

- OE3. Analizar el uso de los hashtags más empleados por dichas cuentas durante la crisis de la COVID-19.

- OE4. Ofrecer una panorámica de la naturaleza de los contenidos que han obtenido más engagement durante la crisis de la COVID-19.

Para lograr la consecución de estos objetivos específicos, se ha empleado la técnica del análisis del contenido (Bryman, 2016). La muestra de plataformas ha sido seleccionada de forma no probabilística (Ruiz Olabuénaga, Aristegui y Melgosa, 1998), teniendo en cuenta los criterios de relevancia, trayectoria en sus respectivos países y participación en iniciativas internacionales de verificación de datos.

La investigación incorpora entidades de España y América Latina. Los sistemas mediáticos de estas regiones se han caracterizado tradicionalmente por presentar problemas y retos compartidos, entre los que cabe destacar: la limitada autonomía periodística, las dificultades de acceso a datos públicos, la alta concentración de medios de comunicación, el alto nivel de polarización de la esfera pública y la influencia de la clase política sobre el periodismo (Baumgartner y Bonafont, 2015; Hallin y Papathanassopoulos, 2002; Masip, Ruiz y Suau, 2018; Ramon-Vegas et al., 2020; Reporteros Sin Fronteras, 2020; Saldaña y Mourão, 2018). La preocupación por el creciente avance de la desinformación también permea los contextos español y latinoamericano. Como señala el Reuters Institute Digital News Report, la desinformación es una amenaza fundamental en países donde "el uso de redes sociales es alto y las instituciones tradicionales son frecuentemente más débiles" (Newman, 2020, p. 17). La inestabilidad política y los altos niveles de politización en países como Argentina, Brasil, Chile o España - sumada a la incertidumbre sobre la pandemia - han facilitado la circulación de información falsa a través de sistemas de mensajería y redes sociales. Con el objetivo de responder a estas dificultades y retos compartidos, en los últimos años han florecido multitud de plataformas de fact-checking independientes en América Latina y España (Stencel y Luther, 2020).

Todas las plataformas examinadas forman parte del NGO model descrito por Graves y Cherubini (2016) para referirse a las iniciativas impulsadas de forma exógena a los medios. Siguiendo el criterio establecido por Humprecht (2020) también se consideró como parte de este modelo a Agência Lupa. Pese a que la plataforma se aloja actualmente en el sitio web de la revista Piauí, se fundó y sigue operando como un proyecto de carácter independiente (Palau-Sampio, 2018). Todos los proyectos son firmantes del código de principios impulsado por la International Fact-Checking Network (IFCN), red que organiza el congreso anual Global Fact-Checking Summit. Además, todas las plataformas consideradas forman parte de la red LATAM Chequea y del proyecto "Información chequeada sobre el Coronavirus".

Para obtener los datos en bruto para realizar el análisis del contenido, se empleó la herramienta de monitorización y análisis de redes sociales Twitonomy (http:// twitonomy.com/). Esta herramienta, creada por Digitonomy, se ha utilizado en otras investigaciones precedentes sobre Twitter (Cárdenas et al., 2020; Marcos García, Alonso Muñoz y Casero Ripollés, 2017; Moya Sánchez y Herrera Damas, 2016; Rojas-Torrijos y Ramon-Vegas, 2017; Usher, 2020). Esta plataforma permite acceder a los contenidos publicados a través de la API (Application Programming Interface) de Twitter. Como limitación esencial, "dicha interfaz únicamente puede retornar los últimos 3.200 tuits publicados por 


\begin{tabular}{|l|c|c|c|c|c|c|}
\hline \multicolumn{1}{|c|}{ Cuenta } & País & $\begin{array}{c}\text { Creación } \\
\text { cuenta }\end{array}$ & IFCN & $\begin{array}{c}\text { LATAM } \\
\text { Chequea }\end{array}$ & Seguidores & $\begin{array}{c}\text { Tuits } \\
\text { analizados }\end{array}$ \\
\hline @agencialupa & Brasil & $19 / 10 / 15$ & Sí & Sí & 173480 & 2642 \\
\hline @Chequeado & Argentina & $9 / 8 / 10$ & Sí & Sí & 279839 & 1831 \\
\hline @malditobulo & España & $30 / 11 / 16$ & Sí & Sí & 277351 & 4368 \\
\hline @Newtral & España & $26 / 9 / 17$ & Sí & Sí & 163457 & 5968 \\
\hline @ColCheck & Colombia & $17 / 2 / 16$ & Sí & Sí & 58618 & 1996 \\
\hline @EcuadorChequea & Ecuador & $19 / 9 / 16$ & Sí & Sí & 11149 & 1122 \\
\hline @ElSabuesoAP & México & $20 / 1 / 15$ & Sí & Sí & 51214 & 3362 \\
\hline @cotejoinfo & Venezuela & $16 / 3 / 16$ & Sí & Sí & 3504 & 1375 \\
\hline
\end{tabular}

Tabla 1. Datos contextuales de las cuentas analizadas y tuits publicados entre los meses de marzo y junio de 2020. Elaboración propia.

cualquier cuenta en abierto" (Rojas-Torrijos y RamonVegas, 2017, p. 921).

Por consiguiente, para garantizar la exhaustividad en la recolección de la muestra y la comparabilidad entre las cuentas analizadas durante cuatro meses, se establecieron dos períodos de recolección del material: del 1 de marzo al 30 de abril de 2020 (Período 1) y del 1 de mayo al 30 de junio de 2020 (Período 2). La extracción de los datos se realizó, respectivamente, el 1 de mayo de 2020 (Período 1) y el 1 de julio de 2020 (Período 2). Considerando la totalidad de la muestra, el número total de tuits descargados fue de $\mathrm{N}=22.664$. El origen de los mensajes se recoge en la Tabla 1.

De cada uno de los mensajes, Twitonomy recuperó datos identificativos clave (cuenta analizada, fecha de publicación), el texto íntegro del tuit y datos sobre engagement (retuits y favoritos). Dicha información en bruto, junto con las métricas generales aportadas por la herramienta, se ha tratado con Microsoft Excel para responder a los objetivos específicos OE1, OE2 y OE3. Para determinar la naturaleza de los contenidos que han obtenido más engagement durante los cuatro meses considerados (OE4), se han seleccionado los 5 contenidos con más retuits y favoritos de cada una de las 8 cuentas examinadas. Estos contenidos son de especial relevancia puesto que son los que más atención han recibido por parte de la audiencia. Esta aproximación ha permitido explorar su naturaleza temática y conocer si los contenidos que más han resonado entre los usuarios tratan sobre la crisis de la COVID-19.

\section{Resultados}

\subsection{Volumen y frecuencia de publicación de contenidos y cifras de engagement}

El análisis revela que todas las plataformas de fact-checking analizadas realizan una intensa tarea en Twitter. Si se observan los datos sobre el volumen y frecuencia de publicación durante los meses de marzo y abril (Tabla 2) y de mayo y junio (Tabla 3), se aprecia que las cuentas que más contenidos publican son @ Newtral, @malditobulo, @ElSabuesoAP y @agencialupa. Dichas cuentas presentan una frecuencia de publicación de al menos 20 tuits por día. Les siguen @Colcheck y @Chequeado (que publican de media alrededor de 15 tuits diarios) y @cotejoinfo y aEcuadorChequea (cuya frecuencia de publicación es menos prolífica, aunque no inferior a 9 tuits de media por día). La mayoría de contenidos publicados son propios, dado que el volumen de informaciones retuiteadas es limitado. La excepción se encuentra en el caso de amalditobulo, cuyo porcentaje de retuits resulta notable (entre marzo y abril, 64,11\% de los contenidos publicados en su timeline fueron retuits; en el caso de mayo y junio, la cifra se situó en el 59,13\%). Estas cifras se explican por el hecho que @ malditobulo retuitea frecuentemente mensajes creados por otras cuentas de la misma empresa (entre ellas, @ maldita_ciencia, @maldita_es o @MalditaTech), además de a otros usuarios y organizaciones.

Las replies (respuestas a otros usuarios de Twitter) son un ingrediente que se emplea de forma moderada en estas cuentas. A juzgar por los datos, se puede encontrar una excepción en el caso de aagencialupa, donde el porcentaje de tuits que son respuestas se eleva hasta el 82,69\% (marzo-abril) y el 81,45\% (mayo-junio). Sin embargo, conviene destacar que la mayoría de respuestas, 1066 de 1075 (marzo-abril) y 1076 de 1093 (mayo-junio) fueron hacia la propia cuenta. Este hecho ilustra que @agencialupa se responde frecuentemente a si misma dentro de hilos donde publica varios mensajes concatenados.

A tenor de los resultados obtenidos, cabe destacar que el uso de enlaces es muy frecuente. Es importante tener en cuenta que "inserción de links en un tuit aporta el contexto que completa la explicación de lo que ahí se expone brevemente" (Rojas-Torrijos y Ramon-Vegas, 
2017, p. 927). En el caso que nos ocupa, los enlaces permiten al lector ahondar en las verificaciones realizadas y publicadas en los sitios web de las plataformas de fact-checking. Como se comentará con más detalle en el apartado 4.2, el uso de hashtags es sistemático, lo que amplía las posibilidades de abrir y viralizar debates sobre los temas tratados.

Si nos centramos en los datos de engagement (retuits y favoritos), se pueden observar dos aspectos de gran relevancia. En primer lugar, se constata que casi la totalidad de los contenidos publicados por @Newtral, @ Chequeado, @ColCheck y @ElSabuesoAP son retuiteados por otras cuentas, hecho que demuestra la relevancia de dichas contribuciones. En las Tablas 2 y 3 se pueden observar, para cada una de las cuentas, el número total de retuits que recibieron, el número medio de retuits por cada tuit retuiteado y los retuits obtenidos por cada
100 seguidores. Este último parámetro es importante para las organizaciones de fact-checking, puesto que "revela la fidelidad de sus seguidores, la confianza en sus mensajes y la credibilidad del medio" (Rojas-Torrijos y Ramon-Vegas, 2017, p. 929). En segunda instancia, en referencia a los tuits marcados como favoritos por los usuarios, los resultados también revelan la alta viralidad de los contenidos publicados por @agencialupa, @Chequado, @Newtral, @ColCheck, @ElSabuesoAP y @ EcuadorChequea, seguida a distancia por la obtenida por los tuits producidos por @malditobulo y @cotejoinfo.

\subsection{Uso de los hashtags en tiempos de la COVID-19}

Uno de los componentes esenciales del lenguaje de Twitter son los hashtags. Como indican Rojas-Torrijos y Ramon-Vegas (2017, p. 927), "la inclusión de etiquetas

\begin{tabular}{|c|c|c|c|c|c|c|c|c|}
\hline & 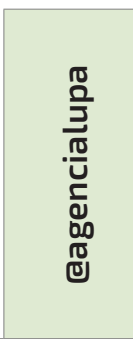 & 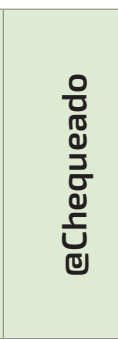 & $\begin{array}{l}0 \\
\frac{0}{J} \\
0 \\
0 \\
.+\frac{7}{0} \\
\frac{\pi}{\pi} \\
\stackrel{E}{\mathbb{E}}\end{array}$ & 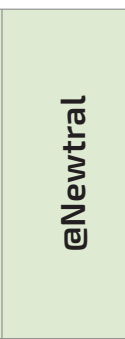 & 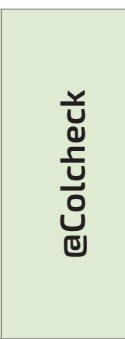 & 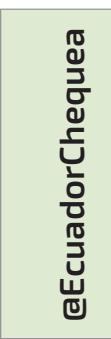 & 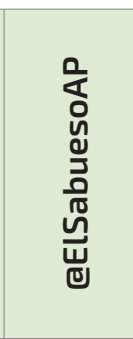 & 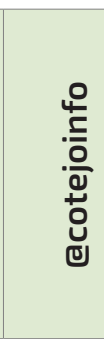 \\
\hline Tuits analizados & 1300 & 907 & 2856 & 3055 & 929 & 571 & 1382 & 737 \\
\hline Tuits por día & 21,31 & 14,87 & 46,82 & 50,08 & 15,23 & 9,36 & 22,66 & 12,08 \\
\hline Retuits & 2 & 24 & 1831 & 5 & 7 & 62 & 26 & 2 \\
\hline$\%$ de los tuits que son retuits & 0,15 & 2,65 & 64,11 & 0,16 & 0,75 & 10,86 & 1,88 & 0,27 \\
\hline Menciones a usuarios & 489 & 690 & 381 & 696 & 349 & 436 & 522 & 282 \\
\hline Menciones por tuit & 0,38 & 0,76 & 0,13 & 0,23 & 0,38 & 0,76 & 0,38 & 0,38 \\
\hline Respuestas & 1075 & 23 & 245 & 62 & 22 & 52 & 61 & 56 \\
\hline$\%$ de los tuits que son respuestas & 82,69 & 2,54 & 8,58 & 2,03 & 2,37 & 9,11 & 4,41 & 7,6 \\
\hline Enlaces & 1291 & 892 & 911 & 3052 & 891 & 356 & 1191 & 571 \\
\hline Enlaces por tuit & 0,99 & 0,98 & 0,32 & 1 & 0,96 & 0,62 & 0,86 & 0,77 \\
\hline Hashtags & 2762 & 1712 & 1347 & 1986 & 1752 & 854 & 1291 & 1252 \\
\hline Hashtags por tuit & 2,12 & 1,89 & 0,47 & 0,65 & 1,89 & 1,5 & 0,93 & 1,7 \\
\hline Tuits retuiteados & 956 & 883 & 904 & 3024 & 903 & 454 & 1320 & 306 \\
\hline$\%$ de tuits retuiteados & 73,54 & 97,35 & 31,65 & 98,99 & 97,2 & 79,51 & 95,51 & 41,52 \\
\hline Número total de retuits & 13721 & 13209 & 58947 & 46034 & 17237 & 4795 & 28756 & 565 \\
\hline Retuits por cada tuit retuiteado & 14,35 & 14,96 & 65,21 & 15,22 & 19,09 & 10,56 & 21,78 & 1,85 \\
\hline Retuits / 100 seguidores & 8,38 & 4,86 & 21,65 & 29,49 & 30,39 & 47,83 & 60,36 & 17,14 \\
\hline Tuits favoritos & 1277 & 883 & 975 & 2988 & 909 & 468 & 1347 & 299 \\
\hline$\%$ de tuits favoritos & 98,23 & 97,35 & 34,14 & 97,81 & 97,85 & 81,96 & 97,47 & 40,57 \\
\hline Número total de favoritos & 47840 & 21177 & 64890 & 61953 & 22489 & 4573 & 49720 & 563 \\
\hline Favoritos por tuit favorito & 37,46 & 23,98 & 66,55 & 20,73 & 24,74 & 9,77 & 36,91 & 1,88 \\
\hline Favoritos / 100 seguidores & 29,21 & 7,79 & 23,83 & 39,68 & 39,65 & 45,61 & 104,36 & 17,08 \\
\hline
\end{tabular}

Tabla 2. Volumen y frecuencia de publicación y cifras de engagement de los tuits publicados durante el período 1 (1 de marzo al 30 de abril de 2020). Elaboración propia. 
puede trasladar una conversación más allá de la propia cuenta y, con ello, atraer y enganchar a un mayor número de usuarios". El análisis de los 10 hashtags más empleados por cuenta durante el período observado demuestra que las plataformas de fact-checking han maximizado la inclusión de etiquetas sobre la COVID19. Los hashtags promovidos por la International Fact Checking Network y la red LATAM Chequea (\#CoronaVirusFacts y \#DatosCoronaVirus) se encuentran entre los más empleados por las diferentes cuentas. El uso compartido y transversal de estos dos hashtags permite que periodistas, ciudadanos y organizaciones de diferentes países puedan encontrar y compartir verificaciones sobre la COVID-19 realizadas en varios territorios.
Estos hashtags específicos se complementan con otros más genéricos, pero con gran capacidad de llegar al público general, entre ellos: \#coronavirus, \#covid19, \#covid2019, \#covid-19, \#covid_19, \#sarscov2 o \#confinamiento. También se publican hashtags sobre la situación del coronavirus en diferentes países como Brasil (\#coronavirusnobrasil), Argentina (\#coronavirusenargentina), España (\#estevirusloparamosunidos, \#yomequedoencasa, \#covid19espana, \#covid19esp) o México (\#coronavirusmx). Dichos hashtags se suman a aquellos ya empleados de forma habitual por las cuentas para difundir las categorías de sus verificaciones (por ejemplo: \#falso, \#verdadero, \#engañoso o \#cuestionable) o para publicitar sus contenidos y

\begin{tabular}{|c|c|c|c|c|c|c|c|c|}
\hline & 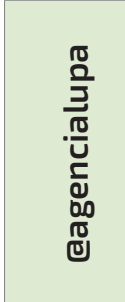 & 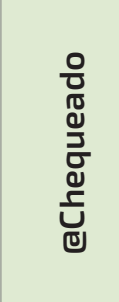 & 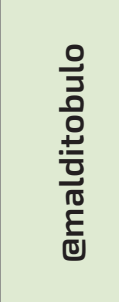 & 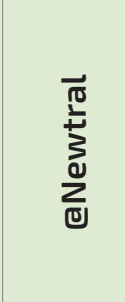 & 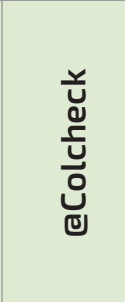 & 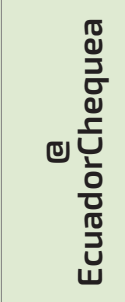 & 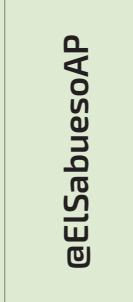 & 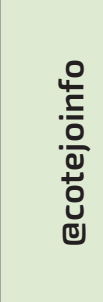 \\
\hline Tuits analizados & 1342 & 924 & 1512 & 2913 & 1067 & 551 & 1980 & 638 \\
\hline Tuits por día & 22 & 15,15 & 24,79 & 47,75 & 17,49 & 9,03 & 32,46 & 10,46 \\
\hline Retuits & 13 & 62 & 894 & 5 & 2 & 74 & 139 & 9 \\
\hline$\%$ de los tuits que son retuits & 0,97 & 6,71 & 59,13 & 0,17 & 0,19 & 13,43 & 7,02 & 1,41 \\
\hline Menciones a usuarios & 475 & 762 & 52 & 656 & 524 & 337 & 550 & 260 \\
\hline Menciones por tuit & 0,35 & 0,82 & 0,03 & 0,23 & 0,49 & 0,61 & 0,28 & 0,41 \\
\hline Respuestas & 1093 & 16 & 26 & 19 & 27 & 65 & 60 & 52 \\
\hline$\%$ de los tuits que son respuestas & 81,45 & 1,73 & 1,72 & 0,65 & 2,53 & 11,8 & 3,03 & 8,15 \\
\hline Enlaces & 1306 & 870 & 588 & 2903 & 1013 & 322 & 1706 & 550 \\
\hline Enlaces por tuit & 0,97 & 0,94 & 0,39 & 1 & 0,95 & 0,58 & 0,86 & 0,86 \\
\hline Hashtags & 2196 & 957 & 650 & 1224 & 1716 & 893 & 1455 & 657 \\
\hline Hashtags por tuit & 1,64 & 1,04 & 0,43 & 0,42 & 1,61 & 1,62 & 0,73 & 1,03 \\
\hline Tuits retuiteados & 847 & 862 & 600 & 2893 & 1038 & 407 & 1795 & 229 \\
\hline$\%$ de tuits retuiteados & 63,11 & 93,29 & 39,68 & 99,31 & 97,28 & 73,87 & 90,66 & 35,89 \\
\hline Número total de retuits & 9155 & 15415 & 12486 & 22888 & 7631 & 3461 & 15130 & 451 \\
\hline Retuits por cada tuit retuiteado & 10,81 & 17,88 & 20,81 & 7,91 & 7,35 & 8,5 & 8,43 & 1,97 \\
\hline Retuits / 100 seguidores & 5,28 & 5,51 & 4,5 & 14 & 13,02 & 31,04 & 29,54 & 12,87 \\
\hline Tuits favoritos & 1286 & 862 & 605 & 2809 & 1043 & 421 & 1801 & 183 \\
\hline$\%$ de tuits favoritos & 95,83 & 93,29 & 40,01 & 96,43 & 97,75 & 76,41 & 90,96 & 28,68 \\
\hline Número total de favoritos & 42138 & 27134 & 15967 & 30977 & 12644 & 3863 & 23730 & 407 \\
\hline Favoritos por tuit favorito & 32,77 & 31,48 & 26,39 & 11,03 & 12,12 & 9,18 & 13,18 & 2,22 \\
\hline Favoritos / 100 seguidores & 24,29 & 9,7 & 5,76 & 18,95 & 21,57 & 34,65 & 46,33 & 11,62 \\
\hline
\end{tabular}

Tabla 3. Volumen y frecuencia de publicación y cifras de engagement de los tuits publicados durante el período 2 (1 de mayo al 30 de junio de 2020). Elaboración propia. 


\begin{tabular}{|c|c|c|}
\hline Cuenta & Período 1: 01/03/2020 - 30/04/2020 & Período 2: 01/05/2020 - 30/06/2020 \\
\hline @agencialupa & $\begin{array}{l}\text { \#coronavirusfacts (1108), \#datoscoronavirus } \\
\text { (920), \#coronavirusnobrasil (554), \#agência- } \\
\text { lupa (50), \#lupanaciência (30), \#coronavirus } \\
\text { (25), \#quarentena (13), \#covid19 (8), \#verifica } \\
\text { (6), \#latamchequea (6) }\end{array}$ & $\begin{array}{l}\text { \#coronavirusfacts (1003), \#datoscoronavirus } \\
\text { (744), \#agêncialupa (227), \#lupanaciência } \\
\text { (97), \#coronaverificado (74), \#agencia- } \\
\text { lupa (16), \#verifica (13), \#lupaeducacao (5), } \\
\text { \#diamundialdomeioambiente (4), \#latam- } \\
\text { chequea (2) }\end{array}$ \\
\hline @Chequeado & $\begin{array}{l}\text { \#datoscoronavirus (433), \#coronavirus } \\
\text { (371), \#coronavirusfacts (340), \#falso } \\
\text { (74), \#fernándezchequeado (66), \#aper- } \\
\text { turadesesiones (43), \#covid2019 (34), } \\
\text { \#asamblealegislativa2020 (33), \#coronavi- } \\
\text { rusenargentina (28), \#verdadero (23) }\end{array}$ & $\begin{array}{l}\text { \#datoscoronavirus (328), \#coronavirusfacts } \\
\text { (138), \#coronavirus (91), \#falso (55), \#latam- } \\
\text { chequea (40), \#verdadero (22), \#falsa (20), } \\
\text { \#verdadera (16), \#engaÑoso (15), \#dengue } \\
\text { (12) }\end{array}$ \\
\hline @malditobulo & $\begin{array}{l}\text { \#coronavirusfacts (568), \#coronavirus (263), } \\
\text { \#covid-19 (43), \#covid_19 (34), \#estevi- } \\
\text { rusloparamosunidos (33), \#covid2019 (30), } \\
\text { \#covid19 (29), \#yomequedoencasa (22), } \\
\text { \#cuarentenatotal (20), \#covid19espana (20) }\end{array}$ & $\begin{array}{l}\text { \#coronavirusfacts (291), \#coronavirus (289), } \\
\text { \#malditalahora (17), \#bulos (15), \#covid19 } \\
\text { (11), \#verdadobulo (7), \#haztemaldito (6), } \\
\text { \#orgullo2020 (3), \#lgtbi (2), \#orgullo (2) }\end{array}$ \\
\hline @Newtral & $\begin{array}{l}\text { \#coronavirus (684), \#datoscoronavirus } \\
\text { (224), \#covid19esp (209), \#covid19 (103), } \\
\text { \#preguntasyrespuestas (74), \#fakes (72), } \\
\text { \#sinverificarnocompartas (70), \#8m (50), } \\
\text { \#confinamiento (39), \#covid_19 (38) }\end{array}$ & $\begin{array}{l}\text { \#covid19 (212), \#coronavirus (145), } \\
\text { \#covid_19 (92), \#covid19esp (65), \#pregun- } \\
\text { tasyrespuestas (51), \#soloenamérica (50), } \\
\text { \#datoscoronavirus (45), \#fakes (33), \#ingre- } \\
\text { somínimovital (25), \#podcast (23) }\end{array}$ \\
\hline @Colcheck & $\begin{array}{l}\text { \#nocomacuento (346), \#falso (266), \#desin- } \\
\text { formación (157), \#nuevochequeo (126), } \\
\text { \#coronavirusfacts (114), \#coronavirus (113), } \\
\text { \#covid_19 (77), \#explicador (57), \#latamche- } \\
\text { quea (42), \#covid-19 (39) }\end{array}$ & $\begin{array}{l}\text { \#falso (357), \#nocomacuento (351), } \\
\text { \#desinformación (154), \#nuevochequeo } \\
\text { (129), \#covid_19 (84), \#explicador (61), } \\
\text { \#chequeomúltiple (39), \#latamchequea (38), } \\
\text { \#desinformaciones (37), \#cuestionable (33) }\end{array}$ \\
\hline @EcuadorChequea & $\begin{array}{l}\text { \#covid19 (220), \#nocomascuento (213), } \\
\text { \#pilas (84), \#ecuador (45), \#coronavirusfacts } \\
\text { (42), \#quédateencasa (37), \#coronavirus } \\
\text { (31), \#ecuadorchequea (25), \#whatsapp (18), } \\
\text { \#coenacional (13) }\end{array}$ & $\begin{array}{l}\text { \#nocomascuento (238), \#covid19 (132), } \\
\text { \#latamchequea (74), \#amallullaytukuychu } \\
\text { (55), \#ecuador (44), \#chequeo24ec (40), } \\
\text { \#cienciasvscovid (29), \#coronavirusfacts } \\
\text { (26), \#pilas (20), \#whatsapp (20) }\end{array}$ \\
\hline @EISabuesoAP & $\begin{array}{l}\text { \#covid-19 (537), \#covid19 (256), \#coronavi- } \\
\text { rusfacts (162), \#coronavirus (82), \#covid (25), } \\
\text { \#loúltimo (22), \#coronavirusmx (16), \#what- } \\
\text { sapp (15), \#fase3 (15), \#emergenciasanitaria } \\
\text { (15) }\end{array}$ & $\begin{array}{l}\text { \#covid-19 (498), \#covid19 (439), \#coronavi- } \\
\text { rusfacts (148), \#covid__19 (74), \#cdmx (35), } \\
\text { \#loÚltimo (35), \#covid (23), \#covid_19 (18), } \\
\text { \#sarscov2 (10), \#nuevanormalidad (10) }\end{array}$ \\
\hline @cotejoinfo & $\begin{array}{l}\text { \#venezuela (225), \#datoscoronavirus (225), } \\
\text { \#coronavirusfacts (210), \#cotejoinfo (189), } \\
\text { \#coronavirus (56), \#covid19 (39), \#cotejo } \\
\text { (23), \#contadorcotejo (23), \#quédateencasa } \\
\text { (22), \#tómateloenserio (21) }\end{array}$ & $\begin{array}{l}\text { \#venezuela (123), \#datoscoronavirus (104), } \\
\text { \#coronavirusfacts (103), \#cotejoinfo (77), } \\
\text { \#olvidadosdelarevolución (30), \#coronavirus } \\
\text { (16), \#ĺndicecatalina (13), \#cotejo4años (13), } \\
\text { \#hipoxia (11), \#factchecking (11) }\end{array}$ \\
\hline
\end{tabular}

Tabla 4. Hashtags más utilizados por las cuentas de Twitter y número de veces en que fueron empleados. Elaboración propia. 


\begin{tabular}{|c|c|c|c|c|c|c|c|c|}
\hline \multirow[b]{3}{*}{ Cuenta } & \multicolumn{4}{|c|}{ Retuits } & \multicolumn{4}{|c|}{ Favoritos } \\
\hline & \multicolumn{2}{|c|}{ Marzo-Abril } & \multicolumn{2}{|c|}{ Mayo-Junio } & \multicolumn{2}{|c|}{ Marzo-Abril } & \multicolumn{2}{|c|}{ Mayo-Junio } \\
\hline & COVID-19 & Otros & COVID-19 & Otros & COVID-19 & Otros & COVID-19 & Otros \\
\hline @agencialupa & 5 & 0 & 3 & 2 & 5 & 0 & 3 & 2 \\
\hline @Chequeado & 5 & 0 & 2 & 3 & 5 & 0 & 2 & 3 \\
\hline @malditobulo & 4 & 1 & 0 & 5 & 4 & 1 & 0 & 5 \\
\hline @Newtral & 5 & 0 & 3 & 2 & 5 & 0 & 2 & 3 \\
\hline @Colcheck & 5 & 0 & 1 & 4 & 5 & 0 & 1 & 4 \\
\hline @EcuadorChequea & 5 & 0 & 4 & 1 & 5 & 0 & 3 & 2 \\
\hline @ElSabuesoAP & 4 & 1 & 3 & 2 & 4 & 1 & 3 & 2 \\
\hline @cotejoinfo & 1 & 4 & 1 & 4 & 1 & 4 & 2 & 3 \\
\hline
\end{tabular}

Tabla 5. Temática de los 5 tuits con más retuits y favoritos durante el período 1 (1 de marzo al 30 de abril de 2020) y el período 2 (1 de mayo al 30 de junio de 2020). Elaboración propia.

\begin{tabular}{|c|c|c|c|}
\hline Cuenta & Fecha & Texto & Retuits \\
\hline @agencialupa & $18 / 3 / 20$ & $\begin{array}{l}\text { Circula nas redes sociais que cientistas israelenses já têm uma vacina } \\
\text { pronta contra o SARS-CoV-2, ou novo coronavírus, microorganismo que } \\
\text { causa a Covid-19. Confira em: bit.ly/33qVa54. \#CoronaVirusFacts \#Datos- } \\
\text { CoronaVirus }\end{array}$ & 836 \\
\hline @aChequeado & $27 / 5 / 20$ & $\begin{array}{l}\text { [NUEVO] No, C5N no publicó en los últimos días imágenes extranjeras } \\
\text { sobre el coronavirus como si fueran locales. Q Ca verificación en esta } \\
\text { nota: chequeado.com/el-explicador/... Por @lugardel y @matydisanti.\#- } \\
\text { DatosCoronavirus \#CoronavirusFacts }\end{array}$ & 617 \\
\hline @malditobulo & $5 / 3 / 20$ & $\begin{array}{l}\text { X Hay una epidemia de bulos sobre el coronavirus Así que lanzamos } \\
\text { nuestra vacuna contra la desinformación... Datos, bulos, explicaciones y } \\
\text { fuentes verificadas. maldita.es/coronavirus/ Entra y paremos juntos las } \\
\text { mentiras. \#coronavirusfacts \#Coronvirus }\end{array}$ & 2410 \\
\hline @Newtral & $25 / 4 / 20$ & $\begin{array}{l}\text { \#FACTCHECK | Pedro Sánchez: «España es de los países del mundo que } \\
\text { más test realiza a su población». Es FALSO } \mathbf{X X}\end{array}$ & 2910 \\
\hline @Colcheck & $11 / 4 / 20$ & $\begin{array}{l}\text { \#FALSO Colombia supuestamente se ubica detrás de Corea del Sur y } \\
\text { El Salvador, pero el ranking NO existe. No encontramos ningún medio } \\
\text { reconocido ni ninguna organización que haya publicado tal listado \#NoCo- } \\
\text { maCuento }\end{array}$ & 3432 \\
\hline EcuadorChequea & $10 / 5 / 20$ & $\begin{array}{l}\text { \#NoComasCuento y evita compartir este vídeo que circula a través de } \\
\text { cadenas de WhatsApp. En esta mentira se utiliza el nombre del Dr. Tasuku } \\
\text { Honjo, Nobel de Medicina, para afirmar que la \#COVID19 tiene origen arti- } \\
\text { ficial. No difundas mentiras y revisa }\end{array}$ & 323 \\
\hline @EISabuesoAP & $7 / 5 / 20$ & $\begin{array}{l}\text { ¡Grrr! @lopezobrador_aseguró que no ha aumentado la violencia contra } \\
\text { mujeres durante la contingencia... iGrrr! Esto es FALSO @y lo desmienten } \\
\text { los registros de llamadas de auxilio, los reportes de ONG y los propios } \\
\text { datos oficiales. }\end{array}$ & 452 \\
\hline @cotejoinfo & $27 / 5 / 20$ & $\begin{array}{l}\text { Se denomina hipoxia a la ausencia de suficiente oxígeno en los tejidos } \\
\text { corporales para poder realizar sus funciones \#CoronaVirusFacts \#Datos- } \\
\text { Coronavirus }\end{array}$ & 13 \\
\hline
\end{tabular}

Tabla 6. Tuit propio sobre COVID-19 más retuiteado en cada cuenta. Elaboración propia. 


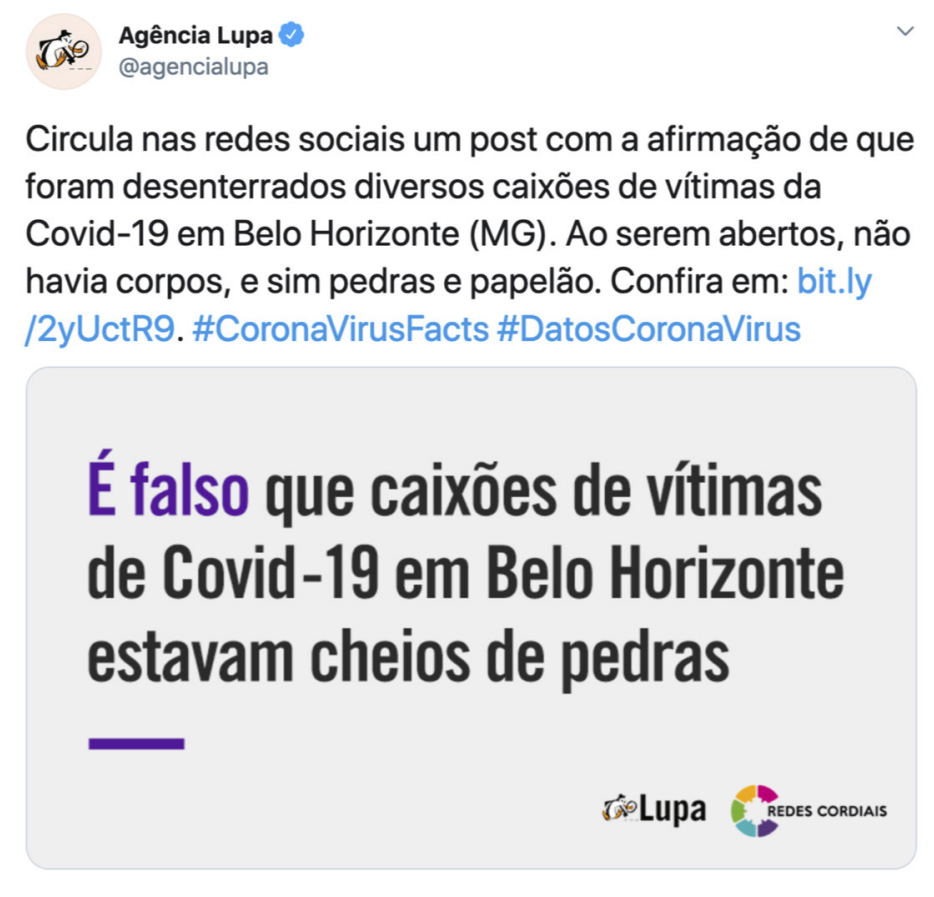

2:01 p. m. $\cdot 2$ may. $2020 \cdot$ TweetDeck

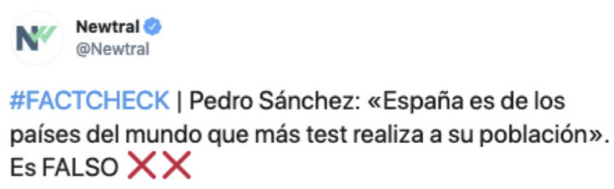
Es FALSO XX

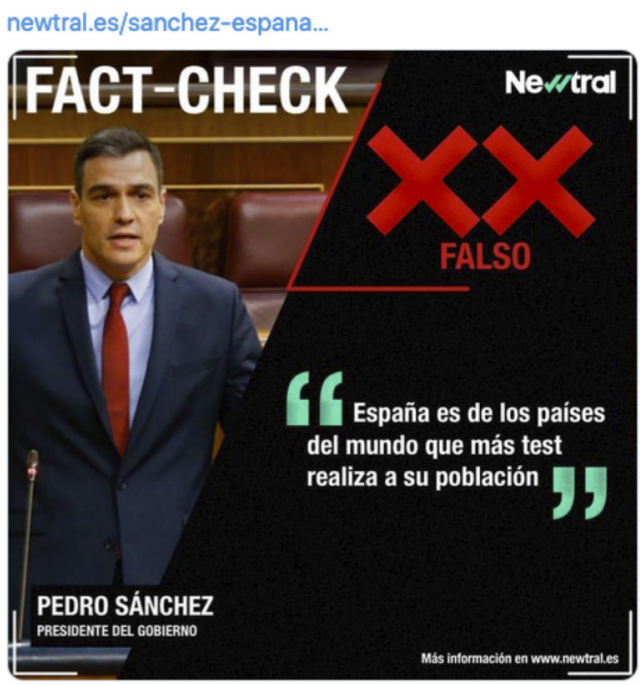

10:29 a. m. $\cdot 25$ abr. $2020 \cdot$ Buffer

Figura 1. Pastillas informativas creadas ad hoc para desmentir afirmaciones sobre la COVID-19. Fuentes: Agência Lupa y Newtral.

fidelizar a los usuarios (como \#haztemaldito o \#cotejo4años).

La inclusión de los hashtags genéricos y específicos sobre la COVID-19 no sólo permite aumentar el tráfico de los contenidos, hecho que desde un punto de vista empresarial resulta beneficioso para las organizaciones estudiadas. Desde la óptica de la responsabilidad periodística, la inclusión de estas etiquetas sobre el coronavirus permite maximizar la circulación de contenidos que contribuyen a desmentir informaciones falsas de carácter sanitario, social y político sobre la pandemia. De esta forma, a través de Twitter las cuentas de fact-checking contribuyen a viralizar la verdad.

\subsection{Contenidos propios con más engagement durante la crisis de la COVID-19}

El análisis de los 5 tuits con más engagement en cada una de las ocho cuentas de fact-checking revela que los contenidos relacionados con la COVID-19 fueron los que obtuvieron un mayor número de retuits y favoritos por parte de los usuarios (Tabla 5). Durante los meses de marzo y abril, los contenidos sobre coronavirus fueron los que más retuits y favoritos obtuvieron en todas las cuentas, a excepción de @cotejoinfo. Esta tendencia se alteró ligeramente durante los meses de mayo y junio, donde tuits sobre otras temáticas obtuvieron más aten- ción en cuentas como @Chequeado, @malditobulo o @ Colcheck.

Si observamos la Tabla 6, que recoge el tuit propio sobre COVID-19 más retuiteado por los usuarios en cada cuenta, podemos ver que las cuestiones verificadas son relevantes y diversas (entre ellas, desmentidos sobre el origen del virus y la existencia de una vacuna para atajarlo, el uso de imágenes de otros países o las cifras de test realizados). Como se aprecia en el ejemplo de @ cotejoinfo, los tuits también se emplean con la finalidad didáctica de explicar a los ciudadanos determinados términos. Esta pequeña muestra también permite ilustrar que se verifican datos y vídeos que circulan a través de las redes sociales y medios de comunicación, pero también se chequean declaraciones de políticos y representantes públicos, como los presidentes del gobierno de España (Pedro Sánchez) y de México (Andrés Manuel López Obrador).

Para ayudar a las audiencias a entender de forma clara las informaciones verificadas, las plataformas de fact-checking tienen en cuenta el potencial de los elementos multimedia: confeccionan pastillas informativas (Figura 1) y también emplean capturas de imagen o fragmentos de vídeos debidamente señalizados como falsos (Figura 2). 
Chequeado

@Chequeado

[NUEVO] No, C5N no publicó en los últimos días imágenes extranjeras sobre el coronavirus como si fueran locales.

La verificación en esta nota: chequeado.com/elexplicador/...

\section{Por @lugardel y @matydisanti. \\ \#DatosCoronavirus \#CoronavirusFacts}

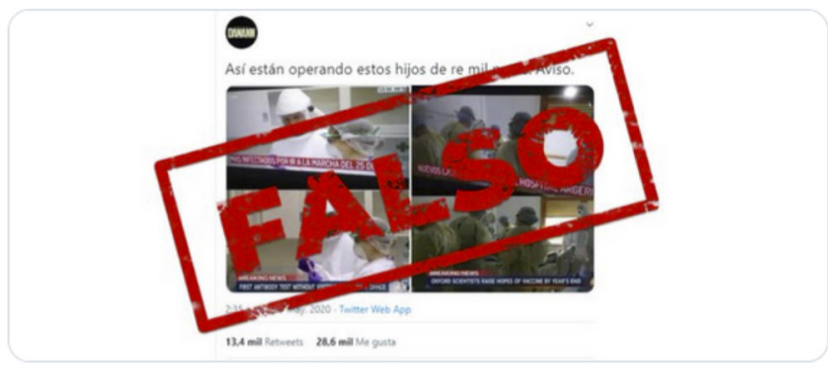

11:42 p. m. - 27 may. 2020 - Buffer
Ecuador Chequea

@ECUADORCHEQUEA

\#NoComasCuento y evita compartir este vídeo que circula a través de cadenas de WhatsApp. En esta mentira se utiliza el nombre del Dr. Tasuku Honjo, Nobel de Medicina, para afirmar que la \#COVID19 tiene origen artificial. No difundas mentiras y revisa:

ow.ly/X6kH50zA10q

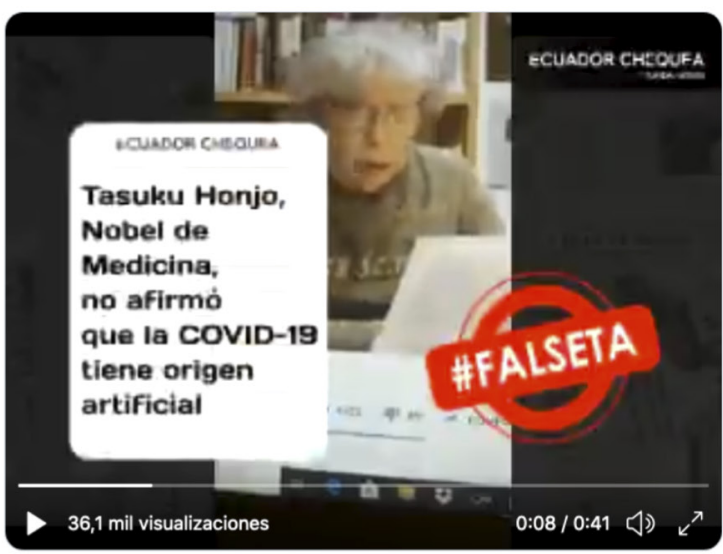

11:00 p. m. . 10 may. 2020 - Hootsuite Inc.

Figura 2. Uso de imágenes y vídeos sobre la COVID-19 marcados como falsos. Fuentes: Chequeado y Ecuador Chequea.

\section{Conclusiones}

Como señala Casero-Ripollés (2020, p. 2), la información "es un mecanismo valioso para orientar a las personas, especialmente en situaciones altamente complejas como la generada por la pandemia del COVID19". En un escenario incierto y cambiante, caracterizado por la infodemia, las plataformas de fact-checking en el ámbito español y latinoamericano se han erigido como actores relevantes en la lucha contra la desinformación vinculada al coronavirus.

Partiendo de metodologías sólidas y agendas informativas marcadas por la relevancia informativa (López-Pan y Rodríguez-Rodríguez, 2020; Palau-Sampio, 2018; Ufarte-Ruiz, Peralta-García y Murcia-Verdú, 2018; Vizoso y Vázquez-Herrero, 2019), los proyectos de fact-checking han realizado una tarea ingente para detectar y difundir verificaciones durante la crisis. Pese a que durante la pandemia las redes sociales se han convertido en un espacio clave para la difusión de bulos e información inexacta y descontextualizada (Masip et al., 2020; Sánchez-Duarte y Magallón-Rosa, 2020), las organizaciones de fact-checking han sabido aprovechar estas mismas redes sociales para combatir la desinformación en línea e incentivar la participación de los usuarios con el objetivo de corresponsabilizarles en la viralización de la verdad.

En particular, se constata como durante la crisis de la COVID-19 Agência Lupa, Chequeado, Maldita.es, Newtral, ColombiaCheck, Ecuador Chequea, El Sabueso - Animal Político y Cotejo han publicado de forma sostenida en Twitter (OE1), obteniendo recibido elevadas cifras de engagement en forma de retuits y favoritos por parte de los usuarios (OEZ). Uno de los ingredientes fundamentales en la producción y circulación de los contenidos ha sido la inclusión de múltiples hashtags sobre la COVID-19 (OE3), incluyendo aquellas etiquetas promovidas por la IFCN y LATAM Chequea (\#CoronaVirusfacts y \#DatosCoronaVirus) y otros hashtags genéricos dirigidos al gran público. Los contenidos relacionados con la COVID-19 han sido los que han obtenido más engagement en estas cuentas (OE4), particularmente durante los meses de marzo y abril de 2020. La versatilidad de Twitter ha permitido publicar un amplio abanico de verificaciones acompañadas de elementos multimedia que ayudan a la presentación de la información.

Ante la situación actual, las plataformas de fact-checking deben seguir trabajando para contraatacar la expansión de la desinformación sobre el coronavirus. Para ello, es preciso que sigan ahondando en los vínculos establecidos entre organizaciones a través de redes internaciones como LATAM Chequea. Ante la avalancha de información a verificar, también es 
imprescindible que estas plataformas apuesten por una mayor colaboración con medios de comunicación. Estas sinergias deben permitir optimizar recursos, potenciar la realización conjunta de verificaciones más complejas y asegurar una mayor visibilidad de los trabajos realizados. También resultará primordial una mayor colaboración entre las plataformas de fact-checking y actores como Google, Facebook y Twitter (Graves y Anderson, 2020). En el momento presente, dichas empresas están trabajando en la monitorización y eliminación de materiales falsos relacionados con la pandemia (Brennen et al., 2020)

Los resultados de este trabajo deben comprenderse en el marco de las limitaciones del estudio: se han analizado 8 cuentas de Twitter operadas por organizaciones independientes de fact-checking de 7 países diferentes (Brasil, Argentina, España, Colombia, Ecuador, México y Venezuela) entre los meses de marzo y junio de 2020. Por consiguiente, los resultados no ahondan en los contenidos publicados por las mismas organizaciones en sus páginas web y otras redes sociales durante el mismo período ni tampoco se aborda el comportamiento de otras organizaciones de verificación de datos pertenecientes a los modelos NGO y newsroom (Graves y Cherubini, 2016).

Aun así, este estudio es un punto de partida para aquellos investigadores que deseen seguir examinando el uso de las redes sociales por parte de las plataformas de fact-checking durante la crisis de la COVID-19. Los retos futuros que se abren con este trabajo incluyen: (1) Realizar un examen pormenorizado de la naturaleza temática, las características lingüísticas y los elementos multimedia empleados en cada uno de los tuits recopilados para este trabajo; (2) Ampliar la muestra para incorporar otras organizaciones en otros países y culturas periodísticas y (3) Abordar las metodologías, estrategias transmedia, recursos y retos de estas plataformas a través de la realización de entrevistas en profundidad con sus responsables. Mediante la aplicación de técnicas cualitativas, futuras investigaciones también deberán analizar el conocimiento que periodistas y los ciudadanos tienen de las plataformas de fact-checking, saber en qué medida las emplean para obtener información fiable sobre la COVID-19 y determinar sus motivaciones para contribuir a la viralización de la verdad durante la pandemia.

\section{Financiación}

Este artículo pertenece al proyecto de investigación "Instrumentos de rendición de cuentas ante la desinformación: impacto de las plataformas de fact-checking como herramientas de accountability y propuesta curri- cular", referencia: PID2019-106367GB-I00, financiado por el Ministerio de Ciencia e Innovación - Gobierno de España.

\section{Referencias}

Amazeen, M. A. (2020). Journalistic interventions: The structural factors affecting the global emergence of fact-checking. Journalism, 21(1), 95-111. https://doi.org/10.1177/1464884917730217

Baumgartner, F.R., y Bonafont L.CH. (2015). All news is bad news: Newspaper coverage of political parties in Spain. Political Communication, 32(2), 268-291. https://doi.org/10.1080/10584609.2014.919 974

Bernal-Triviño, A., y Clares-Gavilán, J. (2019). Uso del móvil y las redes sociales como canales de verificación de fake news. El caso de Maldita.es. El Profesional de La Información, 28(3), 1-8. https://doi. org/10.3145/epi.2019.may.12

Brandtzaeg, P. B., Følstad, A., y Chaparro Domínguez, M. Á. (2018). How journalists and social media users perceive online fact-checking and verification services. Journalism Practice, 12(9), 1109-1129. https://doi.org/10.1080/17512786.2017.1363657

Brennen, J. S., Simon, F.M., Howard, P.N., y Nielsen, R.K. (2020). Types, sources, and claims of COVID-19 misinformation. Reuters Institute for the Study of Journalism. https://reutersinstitute.politics.ox.ac.uk/ types-sources-and-claims-covid-19-misinformation

Cárdenas, L., González de Bustamante, C., y Retis, J. (2020). To tweet for solidarity or just report the news? Comparing social media strategies of Spanish and English-language TV Networks. Television \& New Media. https://doi.org/10.1177/1527476419893792

Casero-Ripollés, A. (2020). Impact of Covid-19 on the media system. Communicative and democratic consequences of news consumption during the outbreak. El profesional de la información, 29(2), e290223. https://doi.org/10.3145/epi.2020.mar.23

Cheruiyot, D., y Ferrer-Conill, R. (2018). Fact-Checking Africa: Epistemologies, data and the expansion of journalistic discourse. Digital Journalism, 6(8), 964-975. https://doi.org/10.1080/21670811.2018.14 93940

Graves, L. (2018). Boundaries Not Drawn: Mapping the institutional roots of the global fact-checking movement. Journalism Studies, 19(5), 613-631. https://doi.org/10.1080/1461670X.2016.1196602

Graves, L., y Anderson, C. W. (2020). Discipline and promote: Building infrastructure and managing algorithms in a "structured journalism" project by professional fact-checking groups. New Media and Society, 22(2), 342-360. https://doi.org/10.1177/1461444819856916

Graves L., y Cherubini F. (2016). The rise of fact-checking sites in Europe. Reuters Institute for the Study of Journalism. https://reutersinstitute.politics.ox.ac.uk/sites/default/files/ research/files/The\%2520Rise\%2520of\%2520Fact-Checking\%2520Sites\%2520in\%2520Europe.pdf

Haigh, M., Haigh, T., y Kozak, N. I. (2018). Stopping fake news: The work practices of peer-to-peer counter propaganda. Journalism Studies, 19(14), 2062-2087. https://doi.org/10.1080/1461670X.2017.1316681

Hallin D., y Papathanassopoulos, 5 (2002). Political clientelism and the media: Southern Europe and Latin America in comparative perspective. Media, Culture and Society, 24(2), 175-195. https://doi. org/10.1177/016344370202400202 
Hameleers, M., y van der Meer, T. G. L. A. (2020). Misinformation and polarization in a high-choice media environment: How effective are political fact-checkers? Communication Research, 47(2), 227-250. https://doi.org/10.1177/0093650218819671

Houston, J. B., McKinney, M. S., Thorson, E., Hawthorne, J., Wolfgang, J. D., y Swasy, A. (2020). The twitterization of journalism: User perceptions of news tweets. Journalism, 21(5), 614-632. https://doi. org/10.1177/1464884918764454

Humprecht, E. (2019). Where "fake news" flourishes: a comparison across four Western democracies. Information Communication and Society, 22(13), 1973-1988. https://doi.org/10.1080/1369 $118 \times .2018 .1474241$

Humprecht, E. (2020). How do they debunk "fake news"? A cross-national comparison of transparency in fact checks. Digital Journalism, 8(3), 310-327. https://doi.org/10.1080/21670811.2019.1691031

Lázaro-Rodríguez, P., y Herrera-Viedma, E. (2020). Noticias sobre Covid-19 y 2019-nCoV en medios de comunicación de España: el papel de los medios digitales en tiempos de confinamiento. El profesional de la información, 29(3), 1-11. https://doi.org/10.3145/epi.2020.may.02

López-Pan, F., y Rodríguez-Rodríguez, J. (2020). El fact checking en España. Plataformas, prácticas y rasgos distintivos. Estudios sobre el Mensaje Periodístico, 26(3), 1045-1065. https://doi.org/10.5209/ esmp.65246

Lowrey, W. (2017). The emergence and development of news fact-checking sites: Institutional logics and population ecology. Journalism Studies, 18(3), 376-394. https://doi.org/10.1080/1461 670X.2015.1052537

Marcos García, S., Alonso Muñoz, L., y Casero Ripollés, A. (2017). Usos ciudadanos de Twitter en eventos políticos relevantes. La \#SesiónDelnvestidura de Pedro Sánchez. Comunicación y Hombre, (13), 25-49. https://doi.org/10.32466/eufv-cyh.2017.13.214.25-49

Masip, P., Ruiz, C., y Suau, J. (2018). Monitoring Media Pluralism in Europe: Application of the Media Pluralism Monitor 2017 in the European Union, FYROM, Serbia \& Turkey. Country Report: Spain. The Centre for media pluralism and media freedom. https://cmpf.eui.eu/ wp-content/uploads/2018/11/Spain_MPM2017_country-report.pdf

Masip, P., Ruiz, C., y Suau, J. (2019). Active audiences and social discussion on the digital public sphere. Review article. El Profesional de la Información, 28(2), e280204. https://doi.org//10.3145/epi.2019. mar.04

Masip, P., Aran-Ramspott, S., Ruiz-Caballero, C., Suau, J., Almenar, E., y Puertas-Graell, D. (2020). Consumo informativo y cobertura mediática durante el confinamiento por el Covid-19: sobreinformación, sesgo ideológico y sensacionalismo. El Profesional de la Información, 29(3), e290312. https://doi.org/10.3145/epi.2020.may.12

Molina-Cabañate, J.P., y Magallón-Rosa, R. (2020). Desinformación y periodismo científico. El caso de Maldita Ciencia. Revista Mediterránea de Comunicación, 11(2), 11-21. https://doi.org/10.14198/ MEDCOM2020.11.2.4

Moreno-Gil, V., Ramon-Vegas, X., y Rodríguez-Martínez, R. (2021). Fact-Checking Interventions as Counteroffensives to Disinformation Growth. Standards, Values, and Practices in Latin America and Spain. Media and Communication, 9(1). [En prensa].

Moya Sánchez, M., y Herrera Damas, S. (2016). Cómo medir el potencial persuasivo en Twitter: propuesta metodológica. Palabra Clave, 19(3), 838-867. https://doi.org/10.5294/pacla.2016.19.3.7

Newman, N. (2020). Executive Summary and Key Findings of the 2019
Report. Reuters Institute for the Study of Journalism. http://www. digitalnewsreport.org/survey/2019/overview-key-findings-2019/

OMS (2 febrero 2020). Rolling updates on coronavirus disease (Covid19). https://www.who.int/docs/default-source/coronaviruse/situation-reports/20200202-sitrep-13-ncov-v3.pdf

Palau-Sampio, D. (2018). Fact-checking and scrutiny of power: Supervision of public discourses in new media platforms from Latin America. Communication and Society, 37(3), 347-365. https://doi. org/10.15581/003.31.3.347-365

Pérez-Dasilva, J.A., Meso-Ayerdi, K., y Mendiguren-Galdospín, T. (2020). Fake news y coronavirus: detección de los principales actores y tendencias a través del análisis de las conversaciones en Twitter. El Profesional de la Información, 29(3), e290308. https://doi. org/10.3145/epi.2020.may.08

Pulido, C.M., Villarejo-Carballido, B., Redondo-Sama, G., y Gómez, A. (2020). Covid-19 infodemic: More retweets for science-based information on coronavirus than for false information. International sociology, 35(4), 377-392. https://doi.org/10.1177/0268580920914755

Ramon-Vegas, X., y Mauri-Ríos, M. (2020). Participación de la audiencia en la rendición de cuentas de los medios de comunicación: instrumentos de accountability y su percepción por parte de los ciudadanos españoles. RAEIC, Revista de la Asociación Española de Investigación de la Comunicación, 7(13), 50-76. https://doi. org/10.24137/raeic.7.13.3

Ramon-Vegas, X., Mauri-Ríos, M., Díaz-Campo, J., y Suárez-Villegas, J.C. (2020). A disconnect in media accountability: Spanish journalists' and citizens' perceptions of established and innovative instruments at the organizational level". Journal of Applied Journalism \& Media Studies. https://doi.org/10.1386/ajms_00040_1

Reporteros Sin Fronteras (2020). Clasificación mundial de la libertad de prensa 2020. https://rsf.org/es/clasificacion

Rodríguez-Pérez, C. (2020). Una reflexión sobre la epistemología del fact-checking journalism: retos y dilemas. Revista de Comunicación, 19(1), 243-258. https://doi.org/10.26441/rc19.1-2020-a14

Rojas-Torrijos, J.L., y Ramon-Vegas, X. (2017). Accountability en las redes sociales. Libros de estilo en continua evolución y retroalimentación a través de Twitter. Revista Latina de Comunicación Social, (72), 915-941. https://doi.org/10.4185/RLCS-2017-1200

Ruiz, C., Masip, P., Micó, J.L., Díaz-Noci, J., Domingo, D. (2010). Conversación 2.0. y democracia. Análisis de los comentarios de los lectores en la prensa digital catalana. Communication \& Society, 23(2), 7-39.

Ruiz Olabuénaga, J.I, Aristegui, I., y Melgosa, L. (1998). Cómo elaborar un proyecto de investigación social. Universidad de Deusto.

Salaverría, R., Buslón, N., López-Pan, F., León, B., López-Goñi, l., y Erviti, M.C. (2020). Desinformación en tiempos de pandemia: tipología de los bulos sobre la Covid-19. El profesional de la información, 29(3), e290315. https://doi.org/10.3145/epi.2020.may.15

Saldaña, M., y Mourão, R. R. (2018). Reporting in Latin America: Issues and perspectives on investigative journalism in the region. The International Journal of Press/Politics, 23(3), 299-323. https://doi. org/10.1177/1940161218782397

Sánchez-Duarte, J.M., y Magallón-Rosa, R. (2020). Infodemia y COVID19. Evolución y viralización de informaciones falsas en España. Revista Española de Comunicación en Salud, S1, 31-41. https://doi. org/10.20318/recs.2020.5417

Singer, J. B. (2018). Fact-Checkers as entrepreneurs: Scalability and 
sustainability for a new form of watchdog journalism. Journalism Practice, 12(8), 1070-1080. https://doi.org/10.1080/17512786.2018.14 93946

Singer, J.B. (2020). Border patrol: The rise and role of fact-checkers and their challenge to journalists' normative boundaries. Journalism. https://doi.org/10.1177/1464884920933137

Stencel, M., y Luther, J. (2020). Annual census finds nearly 300 factchecking projects around the world. Duke Reporters' Lab. https:// reporterslab.org/annual-census-finds-nearly-300-fact-checkingprojects-around-the-world/

Ufarte-Ruiz, M.J., Anzera, G., y Murcia-Verdú, F.J. (2020). Plataformas independientes de fact-checking en España e Italia. Características, organización y método. Revista Mediterránea de Comunicación, 11(2), 23-39. https://doi.org/10.14198/MEDCOM2020.11.2.3

Ufarte-Ruiz, M.J., Peralta-García, L., Murcia-Verdú, F.J. (2018). Fact checking: un nuevo desafío del periodismo. El Profesional de la Información, 27(4), 733-741. https://doi.org/10.3145/epi.2018.jul.02

Usher, B. (2020). The celebrified columnist and opinion spectacle: Journalism's changing place in networked public spheres. Journalism. https://doi.org/10.1177/1464884919897815

Vizoso, Á., y Vázquez-Herrero, J. (2019). Fact-checking platforms in Spanish. Features, organisation and method. Communication and Society, 32(1), 127-142. https://doi.org/10.15581/003.32.1.127-142

\section{CV}

Xavier Ramon-Vegas. Es profesor del Departamento de Comunicación de la Universitat Pompeu Fabra. Doctor en Comunicación por la UPF. Miembro del Grup de Recerca en Periodisme (GRP). Su investigación y docencia se centran en los ámbitos de la ética periodística, la rendición de cuentas de los medios y la comunicación deportiva. Ha publicado en revistas académicas como Digital Journalism, El Profesional de la Información, Revista Latina de Comunicación Social, Communication \& Sport, Ethical Space, Estudios sobre el Mensaje Periodístico o Revista de Comunicación. Ha realizado estancias en la University of Stirling y la University of Glasgow (Reino Unido), la University of Alabama (Estados Unidos) y el Centro de Estudios Olímpicos del
Comité Olímpico Internacional (Suiza). Ha participado en tres proyectos competitivos I+D financiados por el Gobierno de España sobre rendición de cuentas de los medios de comunicación y plataformas de fact-checking. https://upf.academia.edu/XavierRamon

Marcel Mauri-Ríos. Licenciado en periodismo, historia y doctor en comunicación. Es profesor de deontología periodística en el Departamento de Comunicación de la Universitat Pompeu Fabra. Es miembro del Grup de Recerca en Periodisme (GRP) de la UPF. Sus líneas principales de investigación son la deontología periodística, la rendición de cuentas, el periodismo político y la historia del periodismo. Ha realizado estancias de investigación en distintas universidades y ha liderado proyectos competitivos en el ámbito de la historia del periodismo, la deontología y la rendición de cuentas y la desinformación periodística. Ha publicado artículos en revistas académicas y ha escrito en publicaciones especializadas en comunicación.

Ruth Rodríguez-Martínez. Doctora en Periodismo por la Universidad Complutense de Madrid, es profesora en el Departamento de Comunicación de la Universitat Pompeu Fabra (UPF) y miembro del Grup de Recerca en Periodisme (GRP). Sus principales líneas de investigación son la ética en los medios, el fact-checking y el periodismo cultural. Ha participado en diversos proyectos de investigación financiados por el Ministerio de Economía y Competitividad de España y la Comisión Europea. Es coinvestigadora principal de los proyectos "Accountability y culturas periodísticas en España. Impacto y propuesta de buenas prácticas en los medios de comunicación españoles" (CSO2015-66404-P) e "Instrumentos de rendición de cuentas ante la desinformación: impacto de las plataformas de fact-checking como herramientas de accountability y propuesta curricular" (FACCTMedia, PID2019-106367GB-I00).

\section{ocm Observatorio de Cibermedios}

\section{https://observatoriocibermedios.upf.edu/}
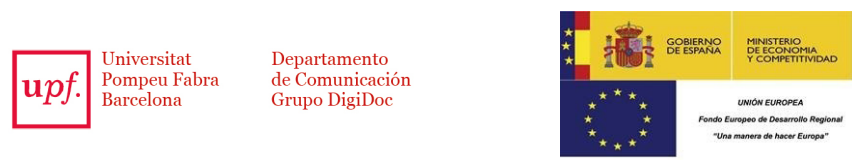

El Observatorio de Cibermedios es una producción del Grupo de Investigación en Documentación Digital y Comunicación Interactiva (DigiDoc) del Departamento de Comunicación de la Universitat Pompeu Fabra.

El Observatorio de Cibermedios (OCM) forma parte del proyecto del Plan Nacional "Narración interactiva y visibilidad digital en el documental interactivo y el periodismo estructurado". RTI2018-095714-B-C21 (MINECO/FEDER), Ministerio de Ciencia, Innovación y Universidades (España). 